\title{
Hemorrhage from cerebral cavernous malformations: a systematic pooled analysis
}

\author{
Bradley A. Gross, MD, ${ }^{1}$ and Rose $\mathrm{Du}, \mathrm{MD}, \mathrm{PhD}^{2}$ \\ 1Division of Neurological Surgery, Barrow Neurological Institute, Phoenix, Arizona; and Department of Neurological Surgery, \\ Brigham and Women's Hospital, Boston, Massachusetts
}

OBJECTIVE The aim of this paper is to define an overall cavernous malformation (CM) hemorrhage rate and risk factors for hemorrhage.

METHODS The authors performed a systematic, pooled analysis via the PubMed database through October 2015 using the terms "cavernoma," "cavernous malformation," "natural history," "bleeding," and "hemorrhage." English-language studies providing annual rates and/or risk factors for $\mathrm{CM}$ hemorrhage were included. Data extraction, performed independently by the authors, included demographic data, hemorrhage rates, and hemorrhage risk factors.

RESULTS Across 12 natural history studies with 1610 patients, the mean age at presentation was 42.7 years old and $52 \%$ of patients (95\% Cl $49 \%-55 \%$ ) were female. Presentation modality was seizure in $30 \%(95 \% \mathrm{Cl} 25 \%-35 \%)$, hemorrhage in $26 \%(95 \% \mathrm{Cl} 17 \%-37 \%)$, incidental in 17\% (95\% Cl 9\%-31\%), and focal deficits only in $16 \%$ of cases $(95 \% \mathrm{Cl}$ $11 \%-23 \%)$. CM location was lobar in 66\% (95\% Cl 61\%-70\%), brainstem in 18\% (95\% Cl 13\%-24\%), deep supratentorial in $8 \%(95 \% \mathrm{Cl} 6 \%-10 \%)$, and cerebellar in $8 \%(95 \% \mathrm{Cl} 5 \%-11 \%)$. Pooling 7 studies that did not assume CM presence since birth, the annual hemorrhage rate was $2.5 \%$ per patient-year over 5081.2 patient-years of follow-up $(95 \% \mathrm{Cl}$ $1.3 \%-5.1 \%$ ). Pooling hazard ratios across 5 studies that evaluated hemorrhage risk factors, prior $\mathrm{CM}$ hemorrhage was a significant risk factor for hemorrhage (HR 3.73, 95\% Cl 1.26-11.1; $p=0.02)$ while younger age, female sex, deep location, size, multiplicity, and associated developmental venous anomalies (DVAs) were not.

CONCLUSIONS Although limited by the heterogeneity of incorporated reports and selection bias, this study found prior hemorrhage to be a significant risk factor for CM bleeding, while age, sex, CM location, size, multiplicity, and associated DVAs were not. Future natural history studies should compound annual hemorrhage rate with prospective seizure and nonhemorrhagic neurological deficit rates.

https://thejns.org/doi/abs/10.3171/2016.3.JNS152419

KEY WORDS cavernous malformation; cavernoma; cavernous hemangioma; natural history; hemorrhage; bleed; epidemiology; vascular disorders

$\mathrm{C}$ AVERNOUS malformations are clusters of endothelium-lined sinusoidal channels filled with blood at various stages of evolution. ${ }^{25,26,30,35}$ These channels, lacking a reinforcing elastin or smooth muscle layer, are directly apposed without intervening neural parenchyma. . $^{25,26}$ Aside from their known epileptogenicity, ${ }^{11,16,18,20,29,34}$ lesion enlargement or extralesional hemorrhage may result in neurological deficits. ${ }^{8,18,22,31}$ Given the fact that these CMs are angiographically occult, $, 5,26,32,33$ the gold standard for their diagnosis is pathological confirmation; ${ }^{16,25,26,33}$ the optimal noninvasive modality to evaluate their presence is MRI. ${ }^{16,32-34}$ The overall prevalence of cerebral cavernous malformations has consistently ranged from $0.4 \%-0.6 \%$ across multiple autopsy and MRI review studies. ${ }^{11,30,34,35,37}$ In contrast, studies evaluating their annual rate of hemorrhage and risk factors for bleeding have yielded heterogeneous results. . $^{2,311,14,19,23,29,31,34}$ The purpose of this analysis is to amalgamate these studies to elucidate annual rates and risk factors for hemorrhage.

\section{Methods}

\section{Study Selection}

Our systematic review was performed in accordance with the PRISMA (Preferred Reporting Items for Systematic reviews and Meta-Analyses) guidelines. ${ }^{27} \mathrm{~A}$ PubMed 
database search using the terms "cavernoma," "cavernous malformation," "natural history," "bleeding," and "hemorrhage" was performed from January 1, 1985, through October 17, 2015. We incorporated English-language studies that provided annual hemorrhage rates for CMs, defined as the ratio of total number of hemorrhages to total number of patient-years of follow-up. Eligibility assessment was performed independently by both reviewers. Studies that did not provide the information to allow an annual hemorrhage rate to be calculated were excluded. In cases of multiple studies from the same patient population, the most recent one providing overall annual hemorrhage rates and risk factors for hemorrhage was used. For our calculations of demographic factors and overall annual hemorrhage rates, we included only studies evaluating a full cohort of patients with cerebral CMs - those studying only subgroups of patients (e.g., pediatric series, brainstem series) were excluded. For our evaluation of hemorrhage risk factors, we initially compiled results across studies that evaluated risk factors via the log-rank test, logistic regression, or Cox regression. Hazard ratios were pooled across studies that provided them.

\section{Data Extraction}

Data extraction was performed independently by both authors and was consistent. We extracted epidemiological data, including patient age, sex, presentation modality, $\mathrm{CM}$ location, multiplicity, and the presence of associated developmental venous anomalies (DVAs). We then calculated the number of hemorrhages and patient-years of follow-up across these studies, also making note of subgroup analyses for hemorrhage risk factors. Hazard ratios were extracted for each risk factor when provided.

\section{Statistical Analysis}

Statistical analysis was performed using the rmeta package in $\mathrm{R}$ version 2.11. Proportions were transformed with the logit transformation, and hazard ratios were logtransformed. Both were pooled using the fixed effects and random effects models. The DerSimonian-Laird estimate was used in the random effects model. Confidence intervals were calculated using the Clopper-Pearson interval. The Cochran Q statistic was used to calculate betweenstudy heterogeneity. The assumption of homogeneity was considered invalid when $\mathrm{p}<0.10$. Results from the random effects model were used. Publication bias was assessed using Egger's test with $p<0.05$ indicating significant bias.

\section{Results}

Our literature search is illustrated in Fig. 1. After an initial screening of 1550 articles, 70 full-text articles were perused for eligibility, affording 12 overall natural history studies $^{2,3,7,11,14,19,22,23,29,31,34,36}$ and 9 studies statistically evaluating risk factors for hemorrhage. $3,4,14,17,19,23,24,29,31$ The majority of variables (incidental, seizure, neurological deficit, hemorrhage, brainstem, multiplicity, and hazard ratios for age, female sex, size, hemorrhage, and multiplicity) had significant between-study heterogeneity; therefore the results of the random effects model were used.

\section{Demographics}

Across 12 natural history studies with 1610 patients, the mean age at presentation was 42.7 years old and $52 \%$ of patients (95\% CI 49\%-55\% from random effects analysis) were female (Table 1). 2,3,7,11,14,19,22,23,29,31,34,36 Across 10 natural history studies, presentation modality was seizure in $30 \%$ (95\% CI $25 \%-35 \%$ ), hemorrhage in $26 \%$ (95\% CI 17\%-37\%), incidental in 17\% (95\% CI 9-31\%), and focal deficits only in $16 \%$ of cases (95\% CI $11 \%-$ 23\%). ${ }^{2,3,7,11,14,19,29,31,36}$ Across 7 studies, CM location was lobar in $66 \%$ (95\% CI 61\%-70\%), brainstem in $18 \%$ (95\% CI $13 \%-24 \%)$, deep supratentorial in $8 \%$ (95\% CI 6\%-10\%), and cerebellar in $8 \%$ (95\% CI 5\%-11\%)., 2,3,722,29,31,34 Across 9 studies, $24 \%$ of patients harbored multiple CMs $(95 \%$ CI 19\%-29\%), 3,7,11,14,22,23,29,31,36 and across 5 studies $18 \%$ of patients had DVAs (95\% CI 14\%-22\%). ${ }^{3,7,14,29,31}$ There was no publication bias except for brainstem location (Egger's test $\mathrm{p}=0.04)$.

\section{Hemorrhage Rates}

Table 2 summarizes overall CM hemorrhage rates in 12 studies. ${ }^{2,3,7,11,14,19,22,23,29,31,34,36}$ All broadly defined a hemorrhage as a symptomatic event with radiographic evidence of hemorrhage. In 2 studies, a CM size increase of at least $20 \%$ was considered adequate radiographic evidence for a hemorrhagic event; ${ }^{19,31}$ on the other hand, 2 other studies specifically required evidence of extralesional hemorrhage or a positive lumbar puncture to define a hemorrhagic event. ${ }^{29,34}$ Two studies only provided overall annual hemorrhage rates per lesion-year, and 1 study that required extralesional hemorrhage or a positive lumbar puncture in addition to a symptomatic event cited an annual rate of $0.7 \%$ per lesion-year. ${ }^{34}$ The other study that allowed for a size increase of $20 \%$ or intralesional/extralesional hemorrhage to define an event cited an annual rate of $4.5 \%$ per lesion-year. ${ }^{19}$ Three early studies assumed CM lesion presence since birth; ;,11,22 the annual hemorrhage rate across these 3 studies ranged from $0.3 \%$ to $2.3 \%$ per patient-year. Pooling results from these 3 studies, over 8265.6 patientyears of follow-up, the annual hemorrhage rate was $1.4 \%$ per patient-year (95\% CI 0.8\%-2.5\%). Seven natural history studies that defined the observation period from presentation until last follow-up provided hemorrhage rates ranging from $0.5 \%$ to $10.0 \%$ per patient-year. ${ }^{2,3,14,23,29,31,36}$ Pooling results from these studies, over 5081.2 patientyears of follow-up, the annual hemorrhage rate was $2.5 \%$ per patient-year (95\% CI 1.3\%-5.1\%; Fig. 2A).

\section{Risk Factors for CM Hemorrhage}

Table 3 summarizes results across 9 studies evaluating risk factors for $\mathrm{CM}$ hemorrhage using log-rank testing, logistic regression, or Cox regression. .,4,14,17,19,23,24,29,31 Prior $\mathrm{CM}$ hemorrhage was a significant risk factor for hemorrhage in 6 of 7 studies. ${ }^{3,14,17,19,23,24,31}$ Deep location was a significant risk factor for hemorrhage in one study ${ }^{31}$ and neared statistical significance as a significant risk factor for hemorrhage in another. ${ }^{19}$ In both of these studies, the definition for CM hemorrhage also included a size of increase of the lesion of at least $20 \%$. Two other studies did not find deep location to be a significant risk factor for 


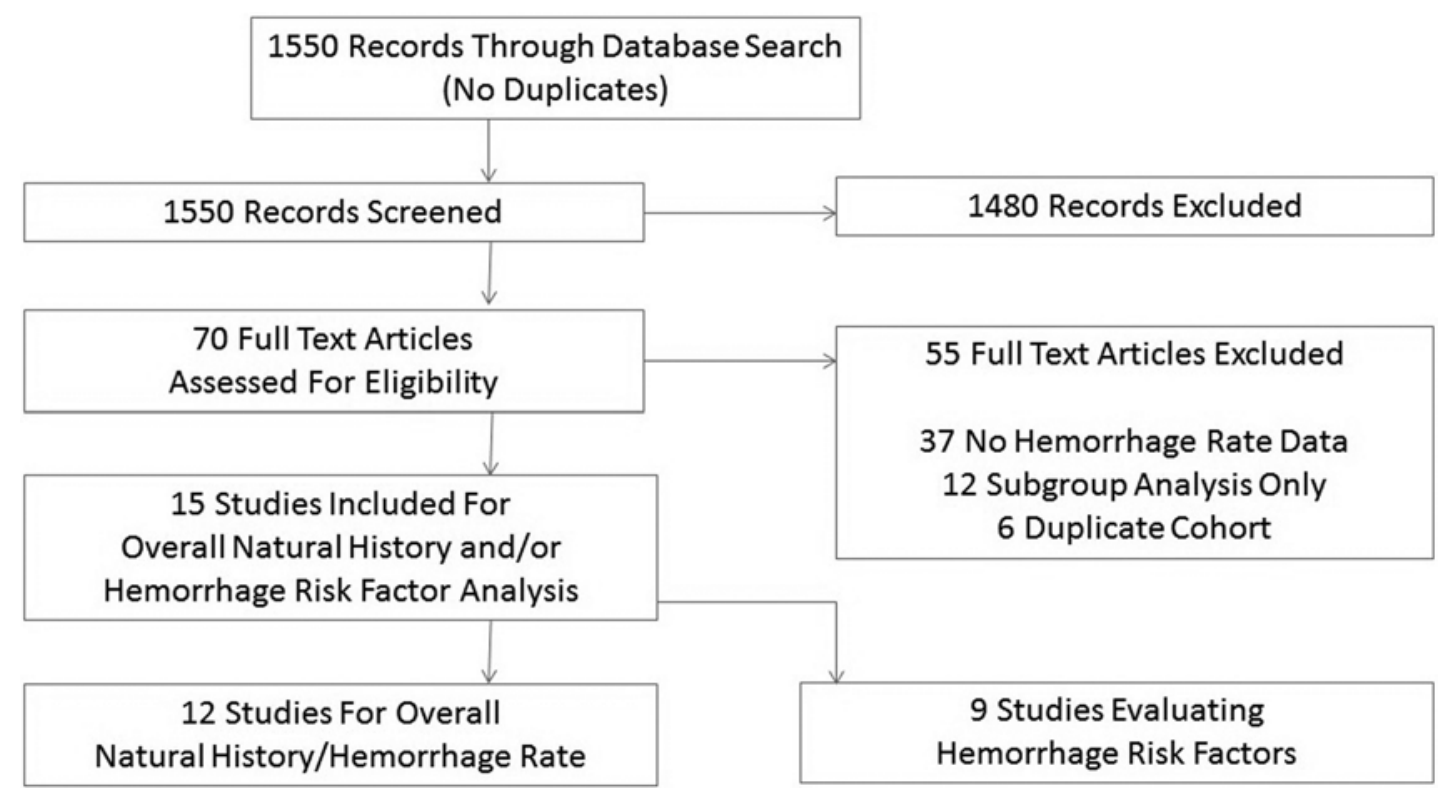

FIG. 1. Literature search results.

CM hemorrhage. ${ }^{4,29}$ Female sex was a significant risk factor for hemorrhage in 2 of the 9 reviewed studies; ${ }^{24,29}$ in 1 study, however, male sex was a significant risk factor for hemorrhage. ${ }^{14}$ One of 4 studies cited younger age as a significant risk factor for hemorrhage. ${ }^{4}$ An associated DVA was seen as a significant risk factor for hemorrhage in one of 5 studies. ${ }^{17}$ Lesion multiplicity was a significant risk factor for hemorrhage in a study that evaluated hemorrhage risk in patient-years, ${ }^{14}$ in another study that evaluated risk per lesion-year, a trend was in fact seen toward protection from hemorrhage. ${ }^{17}$ Five other studies did not find lesion multiplicity to be a significant risk factor for hemorrhage. ${ }^{3,19,23,24,31}$ CM size was not a significant risk factor for hemorrhage in any of the 3 studies evaluating this risk factor. ${ }^{19,24,29}$

Five studies provided hazard ratios for hemorrhage risk factors (Table 4; Fig. 2B-H). 4,14,17,19,24 These were pooled, revealing only prior $\mathrm{CM}$ hemorrhage as a significant risk factor for hemorrhage (HR 3.73, 95\% CI 1.26-11.1; $\mathrm{p}=$ $0.02)$. Younger age (HR 1.03, 95\% CI 0.91-1.17; $\mathrm{p}=0.62)$, female sex (HR 1.02, 95\% CI 0.72-1.43; p = 0.92), deep location (HR 1.14, 95\% CI 0.76-1.71; p = 0.52), size (HR $1.07,95 \%$ CI $0.88-1.30 ; p=0.52$ ), multiplicity (HR 1.10, 95\% CI $0.73-1.65 ; \mathrm{p}=0.65)$, and associated DVAs (HR $1.28,95 \%$ CI $0.75-2.17$; $=0.36$ ) were not significant risk factors for hemorrhage.

\section{Discussion}

Hemorrhage from cerebral CMs is the most studied aspect of their natural history. 2,3,7,11,14,19,22,23,29,31,34,36 Nevertheless, there is still considerable controversy and variability in cited rates and risk factors for hemorrhage. Various study designs and hemorrhage definitions have contributed to this heterogeneity. Specifically, studies that derive their cohort of patients from an institutional review of imaging are likely to harbor more benign CMs with smaller proportions of hemorrhagic lesions..$^{11,34}$ Owing to both the study design itself and the resultant smaller proportion of hemorrhagic lesions in the cohort, the calculated annual hemorrhage rate may be an underestimate due to selection bias. On the other hand, studies from surgical centers that evaluate a "pre-treatment" hemorrhage rate may report inflated rates due to referral bias and a high proportion of hemorrhagic CMs. ${ }^{2}$ As a means to curtail these limitations and bias, we have pooled results across the literature. Across 3 early studies that assumed CM presence since birth, the annual hemorrhage rate was $1.4 \%(95 \%$ CI $0.8 \%-2.5 \%)$. $^{7,11,22}$ Across 7 studies that began followup at the time of clinical presentation, the annual hemorrhage rate was $2.5 \%$ (95\% CI 1.3\%-5.1\%). ${ }^{2,3,14,23,29,31,36}$ As expected, this approach provided a higher hemorrhage rate given the smaller amount of provided patient-years of follow-up. Generally, modern approaches to natural history have espoused this follow-up approach, which bears particular relevance for CMs given the accumulating literature suggesting that a substantial proportion of these lesions are acquired. ${ }^{5,6,12,18}$ However, overall annual hemorrhage rates bear little meaning for individualized patient management. Stratified rates based on known risk factors have far greater utility in understanding disease pathology for treatment planning and for patient counseling.

\section{Hemorrhage Risk Factors}

Nearly ubiquitously across our reviewed studies, hemorrhage was a significant risk factor for subsequent bleeding, 3,14,17,19,23,24 our pooled hazard ratio for this risk factor was $3.73(95 \%$ CI 1.26-11.1, $\mathrm{p}=0.02)$. Annualized hemorrhage rates for unruptured $\mathrm{CMs}$ are generally consistent in the literature-ranging from $0.4 \%$ to $0.6 \%$ per patient-year across 3 studies. ${ }^{2,3,23}$ On the other hand, those for ruptured CM vary widely, from $4.5 \%$ per patient-year to $22.9 \%$ per patient-year across numerous studies. ${ }^{2-4,14,19,23}$ This wide range is likely in part due to varying follow-up periods, as hemorrhage clustering has been consistently demonstrated 


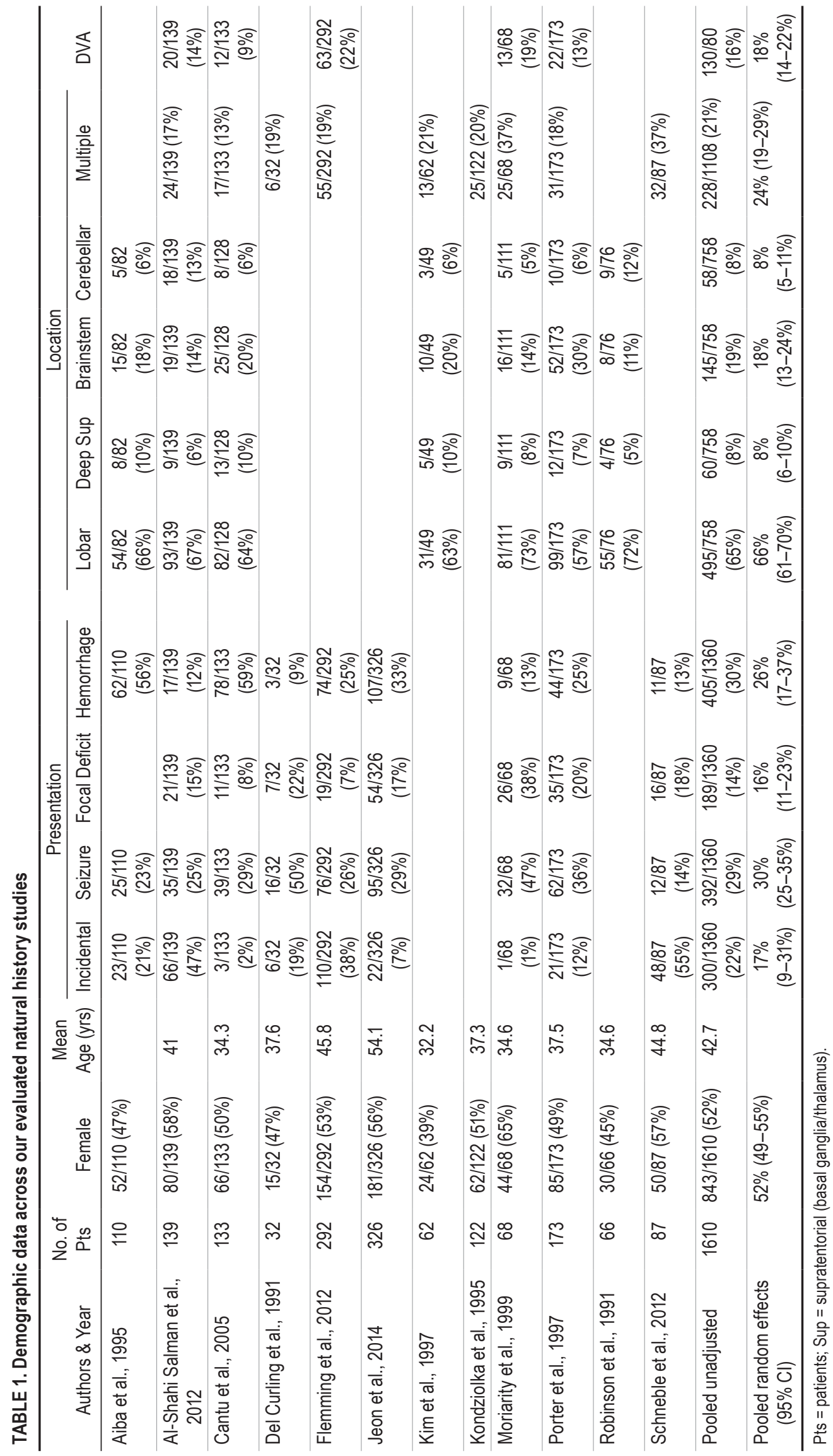


TABLE 2. Cavernous malformation hemorrhage rates*

\begin{tabular}{|c|c|c|c|c|}
\hline Authors \& Year & No. of Bleeds & $\begin{array}{l}\text { Patient-Yrs } \\
\text { Since Birth }\end{array}$ & $\begin{array}{l}\text { Patient-Yrs } \\
\text { Follow-Up }\end{array}$ & Annual Hemorrhage Rate \\
\hline Aiba et al., 1995 & 46 & & 460.5 & $10.0 \% /$ patient-yr \\
\hline Al-Shahi Salman et al., 2012 & 6 & & 1177 & $0.5 \% /$ patient-yr \\
\hline Cantu et al., 2005 & 78 & 4561 & & 1.7\%/patient-yr \\
\hline Del Curling et al., 1991 & 3 & 1195 & & $0.3 \% / p a t i e n t-y r$ \\
\hline Flemming et al., 2012 & 48 & & 2035 & $2.4 \% / p a t i e n t-y r$ \\
\hline Jeon et al., 2014 & & & & $4.5 \% / l e s i o n-y r$ \\
\hline Kim et al., 1997 & 57 & 2509.6 & & $2.3 \% /$ patient-yr \\
\hline Kondziolka et al., 1995 & 9 & & 341.6 & $2.6 \% /$ patient-yr \\
\hline Moriarity et al., 1999 & 11 & & 352.9 & 3.1\%/patient-yr \\
\hline Porter et al., 1997 & 7 & & 427 & 1.6\%/patient-yr \\
\hline Robinson et al., 1991 & & & & $0.7 \% / l e s i o n-y r$ \\
\hline Schneble et al., 2012 & 9 & & 287.2 & 3.1\%/patient-yr \\
\hline Pooled unadjusted congenital studies $(n=3)$ & 138 & 8265.6 & & 1.7\%/patient-yr \\
\hline Pooled random effects congenital studies & & & & 1.4\%/patient-yr (95\% Cl 0.8-2.5\%) \\
\hline Pooled unadjusted follow-up studies $(n=7)$ & 136 & & 5081.2 & 2.7\%/patient-yr \\
\hline Pooled random effects follow-up studies & & & & 2.5\%/patient-yr (95\% Cl 1.3-5.1\%) \\
\hline
\end{tabular}

* Three studies (Cantu et al., Del Curling et al., and Kim et al.) assumed lesion presence since birth and were pooled separately. Two studies (Jeon et al. and Robinson et al.) provided hemorrhage rates in lesion-years only.

in numerous studies, particularly within the first 2-3 years after an initial bleed. ${ }^{3,4,14,17}$ Indeed, 2 studies reporting the rehemorrhage rate within the 1st year reported relatively consistent rehemorrhage rates of $14 \%{ }^{4}$ and $18 \% .^{14}$

Although 2 studies suggested female sex to be a significant risk factor for hemorrhage, ${ }^{24,29}$ another suggested male sex to be a significant risk factor..$^{14}$ Our pooled analysis demonstrated no significance of sex on the risk of CM hemorrhage. Although not formally statistically evaluated in our reviewed studies, multiple reports have not demonstrated pregnancy to be a significant risk factor for CM hemorrhage. ${ }^{14,21,38}$ One of our reviewed studies noted that 12 patients with confirmed diagnoses of cerebral CMs subsequently had no symptoms during pregnancy. ${ }^{14}$ In one study of 64 women harboring CMs during pregnancy, the annual hemorrhage rate during pregnancy was $3.4 \%$ per patient-year (2\% per patient-year in the single CM group and $4 \%$ in the multiple CM group); the authors concluded that this did not substantially differ from the general population of patients with CMs. ${ }^{21}$ In another study of 186 women harboring cerebral CMs, the annual hemorrhage rate during pregnancy was $1.15 \%$ per patient-year as compared with $1.01 \%$ during nonpregnant childbearing years (relative risk 1.13, 95\% CI 0.34-3.75). ${ }^{38}$ Two of 3 hemorrhages occurring during pregnancy resulted in mild permanent deficits in the mother; all 3 children were born healthy at term, 2 via cesarean section.

Although potentially confounded by a recent bleed increasing the apparent size of the lesion, size as an independent variable was not a significant risk factor for hemorrhage. Similarly, although we could not pool results for analyses of the impact of Zabramski grade ${ }^{39}$ on hemorrhage risk, this factor, almost by definition, is confounded by hemorrhage (Table 5). Type I lesions, which were shown to have a greater risk of hemorrhage than others in
1 study, ${ }^{19}$ are hemorrhagic by definition. We did not find lesion multiplicity to be a significant risk factor for hemorrhage. One study that found this factor to be significant evaluated hemorrhage risk on a per-patient rather than perlesion approach; ${ }^{14}$ as such, the additive effect of harboring multiple lesions may have led to their result rather than an intrinsic proclivity of patients harboring multiple lesions to have a greater risk of hemorrhage from each CM. Radiographically apparent associated DVAs were not found to be a significant risk factor for hemorrhage; this may be in part due to the fact that all CMs may be associated with a venous component, often occult on standard MRI.,10,16,18 In the often-cited surgical series of 300 brainstem CMs from the Barrow Neurological Institute, all were found in association with a venous component at surgery despite only seeing a venous anomaly in $28 \%$ of preoperative MRI studies. ${ }^{1}$ Another study that evaluated 20 patients harboring $23 \mathrm{CMs}$ on 7-T MR images found abnormal venous structures in all cases. ${ }^{10}$ Prior reports have postulated this venous component to be crucial to CM development..$^{10,18}$

Studies with less stringent radiographic definitions of hemorrhage (including lesion size increases) reported greater rates of hemorrhage for deep CMs. ${ }^{19,31}$ This likely reflects the greater sensitivity of adjacent eloquent parenchyma to lesion morphological changes and smaller bleeds. Nevertheless, our pooled review did not demonstrate deep location to be a significant risk factor for hemorrhage overall. Indeed, it is difficult to provide a pathophysiological basis to explain a greater innate proclivity for deep CMs to hemorrhage as opposed to superficial lesions.

One of our reviewed studies reported a lower rate of hemorrhage among patients taking antiplatelet or antithrombotic medication. ${ }^{36}$ In this study, no hemorrhages occurred over 82.4 patient-years of follow-up for 16 pa- 
A

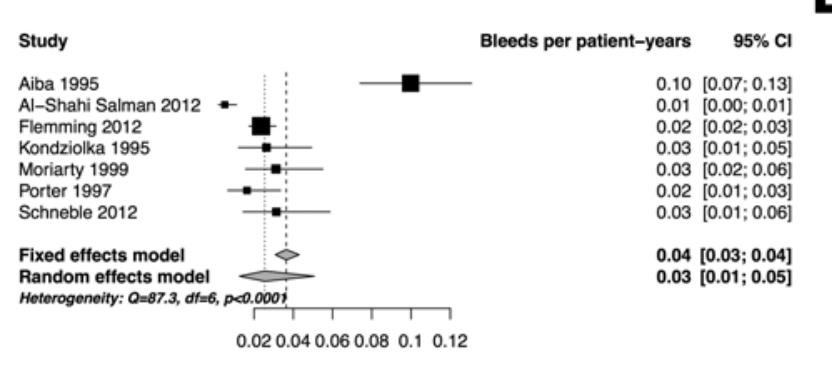

B

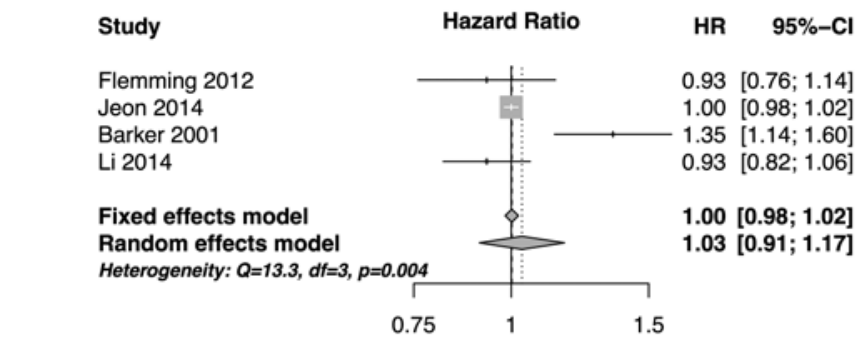

C

Female Sex

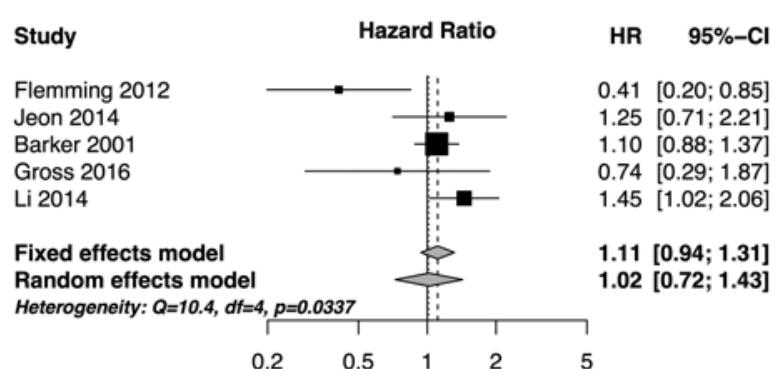

Deep Location

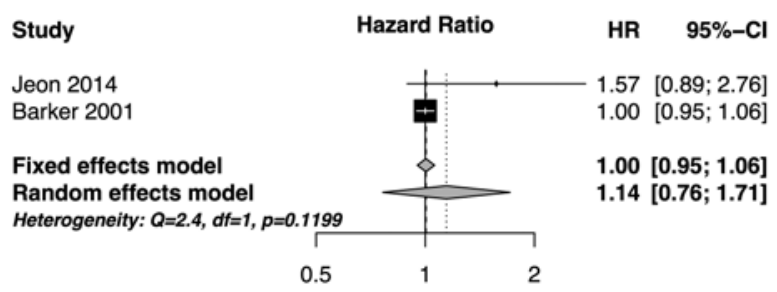

E

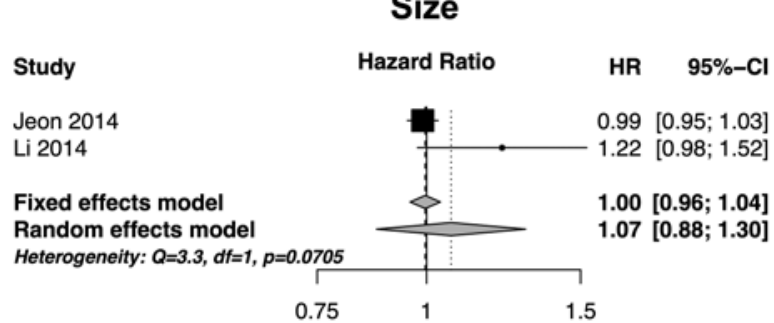

Prior Hemorrhage

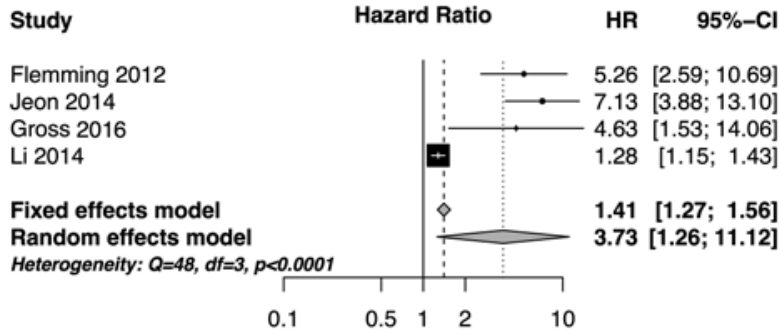

Multiplicity

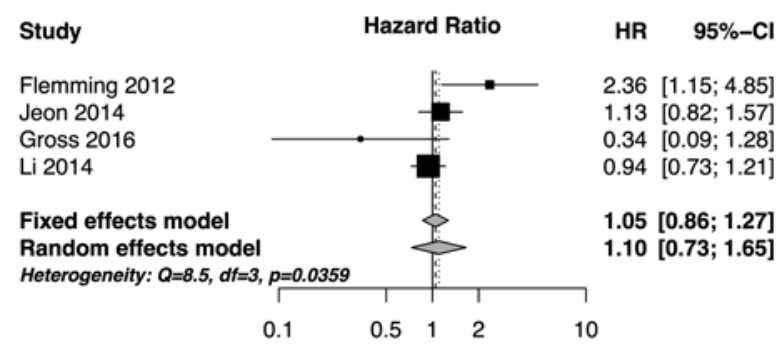

DVA

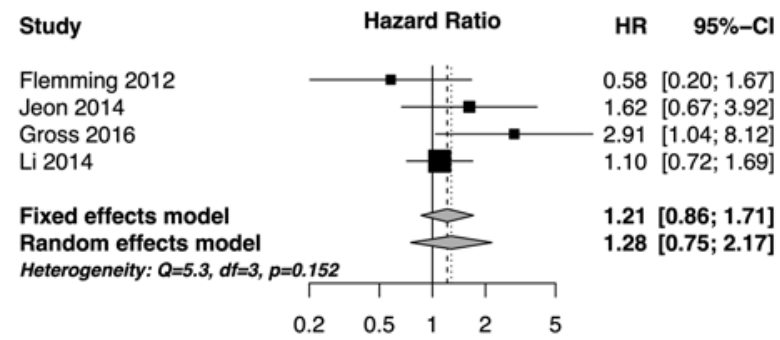

FIG. 2. Forest plots for overall annual hemorrhage rate (A) and hemorrhage risk factors: younger age (B), female sex (C), deep location (D), size (E), prior hemorrhage (F), multiplicity (G), and associated DVAs (H).

tients receiving antiplatelet or antithrombotic therapy $(\mathrm{p}=$ 0.08 for comparison with 71 patients not receiving blood thinners). The authors suggested that the trend toward a lower rate of hemorrhage in patients on anticoagulants may be due to the alleviation of venous congestion. Eleven patients were receiving antiplatelet therapy (9 receiving aspirin, 2 receiving clopidogrel) and 5 were taking warfarin. In another study of 40 patients receiving antithrombotic therapy, the annual prospective hemorrhage rate was $0.41 \%$ per patient-year (one hemorrhage in a patient taking aspirin) over a total follow-up of 258 patient-years (median 6.5 years); 32 patients were receiving an antiplatelet agent: 6 were on anticoagulation, and 2 were on both. ${ }^{15}$ In one study of 350 patients undergoing thrombolysis with recombinant tissue-type plasminogen activator for acute stroke, there was no significant difference in rates of symptomatic intracranial hemorrhage and parenchymal hemorrhage among patients harboring cerebral CMs as compared with those who did not. ${ }^{13}$

None of our reviewed studies evaluated the impact of prior radiation on risk of CM hemorrhage. In one subgroup report of 32 patients with radiation-induced CMs, the median latency from radiation treatment to $\mathrm{CM}$ diagnosis was 12.0 years. ${ }^{9}$ The risk of hemorrhage from radiation- 
TABLE 3. Risk factors for hemorrhage*

\begin{tabular}{|c|c|c|c|c|c|c|c|}
\hline Authors \& Year & Younger Age & Female Sex & Deep Location & Size & Hemorrhage & Multiplicity & DVA \\
\hline Al-Shahi Salman et al., 2012† & & 0.29 & & & $<0.0001$ & 0.7 & 0.3 \\
\hline Barker et al., 2001‡ & $<0.001$ & 0.3 & 1.0 & & & & \\
\hline Flemming et al., $2012 \ddagger$ & 0.47 & $0.016 \pi$ & & & $<0.001$ & 0.019 & $0.3 \pi$ \\
\hline Gross et al., 2016‡ & & $0.52 \rrbracket$ & & & 0.007 & $0.11 \rrbracket$ & 0.04 \\
\hline Jeon et al., 2014‡ & 0.61 & 0.45 & 0.12 & 0.60 & $<0.001$ & 0.71 & 0.29 \\
\hline Kondziolka et al., $1995 \S$ & & 0.97 & & & 0.028 & 0.15 & \\
\hline Li et al., 2014ł & $0.28 \pi$ & 0.041 & & 0.08 & 0.029 & $0.80 \rrbracket$ & 0.65 \\
\hline Moriarity et al., $1999 \dagger$ & & 0.04 & $>0.5$ & 0.79 & & & \\
\hline Porter et al., 1997† & & 0.77 & 0.0003 & & 0.47 & 0.61 & \\
\hline
\end{tabular}

* Boldface type indicates statistical significance.

$\dagger p$ values are from log-rank tests.

$\ddagger p$ values are from hazard ratios.

$\S p$ values are from logistic regression.

I Results suggest the risk factor protects against hemorrhage.

induced CMs was $4.2 \%$ per person-year compared with $2.3 \%$ for nonradiation-induced CMs $(\mathrm{p}=0.556)$. Hemorrhagic radiation-induced $\mathrm{CM}$ had relatively high rehemorrhage rates $(11.0 \%$ per person-year vs $5.5 \%, \mathrm{p}=0.529)$. Asymptomatic radiation-induced CMs also had a greater prospective risk of hemorrhage than asymptomatic nonradiation-induced CMs $(4.2 \%$ vs $0.35 \%, \mathrm{p}=0.118) .{ }^{9}$

\section{Natural History of CMs}

The natural history of an untreated cerebral CM must encompass not only the prospective risk of hemorrhage but also of seizures and focal deficits in addition to the psychological burden of harboring an untreated vascular malformation of the brain. The latter has not been well studied. As we illustrate, the risk of hemorrhage is approximately $2.5 \%$ per patient-year overall, influenced primarily by presentation modality (hemorrhagic vs nonhemorrhagic) as unruptured CMs have a relatively low prospective risk of hemorrhage $\left(0.4 \%-0.6 \%\right.$ per patient-year), ${ }^{2,3,23}$ that increases substantially if the lesion bleeds..$^{2-4,14,19,23}$ The prospective risk of a focal deficit independent of hemorrhage has been evaluated in 2 studies that described an overall clinical event rate for CMs: the sum of the hemorrhage and focal deficit (in the absence of hemorrhage) rates. In the study by Porter et al., the overall annual hemorrhage rate was $1.6 \%$, increasing to $4.2 \%$ when including nonhemorrhagic events. ${ }^{31}$ Thus, the annual rate of nonhemorrhagic neurological events in this study was $2.6 \%$. The authors noted that these events occurred exclusively in deep lesions; the annual hemorrhage rate in this cohort was $4.1 \%$, increasing to $10.6 \%$ per patient-year when including nonhemorrhagic events. Hemorrhage or a focal deficit at presentation and deep location were each significant risk factors for the occurrence of hemorrhage or a clinical event at follow-up. Importantly, there was no significant difference in the degree of recovery between hemorrhagic and nonhemorrhagic clinical events - approximately one-third of patients had resolution of symptoms, one-third improved, and one-third suffered permanent deficits. In another study that provided an aggregate rate of hemorrhage or focal deficits, the 5-year risk was $9.3 \%$ for patients presenting incidentally or with seizures, increasing to $42.4 \%$ for patients presenting with focal deficits or hemorrhage. ${ }^{3}$ The prospective risk of seizures in patients with cerebral CMs has been evaluated in only a paucity of studies..$^{20,28,29} \mathrm{In}$ one, the annual seizure risk was $2.4 \%$ per person-year, and the risk of recurrent seizures was $5.5 \%$ per patient-year. ${ }^{29}$ In another more recent study, the 5-year risk of a first seizure was $6 \%$ in patients presenting with either intracranial

TABLE 4. Hazard ratios for risk factors for hemorrhage evaluated across natural history studies*

\begin{tabular}{|c|c|c|c|c|c|c|c|}
\hline Authors \& Year & Younger Age & Female Sex & Deep Location & Size & Hemorrhage & Multiplicity & DVA \\
\hline $\begin{array}{c}\text { Barker et al., } \\
2001\end{array}$ & $1.35(1.14-1.61)$ & $1.1(0.9-1.4)$ & $1.0(0.95-1.06)$ & & & & \\
\hline $\begin{array}{l}\text { Flemming et al., } \\
2012\end{array}$ & $0.93(0.76-1.14)$ & $0.41(0.20-0.85)$ & & & $5.26(2.59-10.7)$ & $2.36(1.15-4.86)$ & $0.58(0.20-1.65)^{*}$ \\
\hline $\begin{array}{c}\text { Gross et al., } \\
2016\end{array}$ & & $0.74(0.29-1.86)$ & & & $4.63(1.53-14.1)$ & $0.34(0.09-1.27)$ & $2.91(1.04-8.09)$ \\
\hline Jeon et al., 2014 & $1.00(0.98-1.02)$ & $1.25(0.71-2.22)$ & $1.57(0.89-2.76)$ & $0.99(0.95-1.03)$ & $7.13(3.88-13.1)$ & $1.13(0.59-2.17)$ & $1.62(0.67-3.92)$ \\
\hline Li et al., 2014 & $0.93(0.82-1.06)$ & $1.45(1.02-2.05)$ & & $1.22(0.98-1.53)^{*}$ & $1.28(1.03-1.59)$ & $0.94(0.56-1.57)^{*}$ & $1.10(0.72-1.70)^{*}$ \\
\hline $\begin{array}{l}\text { Pooled random } \\
\text { effects }\end{array}$ & $\begin{array}{c}1.03(0.91-1.17) \\
p=0.62\end{array}$ & $\begin{array}{c}1.02(0.72-1.43) \\
p=0.92\end{array}$ & $\begin{array}{c}1.14(0.76-1.71) \\
p=0.52\end{array}$ & $\begin{array}{c}1.07(0.88-1.30) \\
p=0.52\end{array}$ & $\begin{array}{c}3.73(1.26-11.12) \\
p=0.02\end{array}$ & $\begin{array}{c}1.10(0.73-1.65) \\
p=0.65\end{array}$ & $\begin{array}{c}1.28(0.75-2.17) \\
p=0.36\end{array}$ \\
\hline
\end{tabular}

* Boldface type indicates statistical significance. HRs are reported with $95 \% \mathrm{Cls}$ in parentheses.

$\dagger$ Results from univariate analysis. 
TABLE 5. Summary of the Zabramski MRI classification for CMs

\begin{tabular}{|c|c|c|c|}
\hline Type & Description & $\begin{array}{c}\text { T1 MRI } \\
\text { Appearance }\end{array}$ & T2 MRI Appearance \\
\hline I & Subacute hemorrhage & Hyperintense & $\begin{array}{l}\text { Hyper- or hypointense; } \\
\text { hypointense rim }\end{array}$ \\
\hline II & $\begin{array}{l}\text { Loculated hemorrhage } \\
\& \text { thrombosis of } \\
\text { varying age }\end{array}$ & $\begin{array}{l}\text { Reticulated, } \\
\text { mixed } \\
\text { signal }\end{array}$ & $\begin{array}{l}\text { Reticulated, mixed } \\
\text { signal; hypointense } \\
\text { rim }\end{array}$ \\
\hline III & Chronic hemorrhage & $\begin{array}{l}\text { Iso- or hy- } \\
\text { pointense }\end{array}$ & Hypointense \\
\hline IV & $\begin{array}{c}\text { Punctate hypointense } \\
\text { lesions on gradient } \\
\text { echo sequences }\end{array}$ & Occult & Occult \\
\hline
\end{tabular}

* Based on the system from the study by Zabramski et al.

hemorrhage or focal neurological deficits without seizures, decreasing to $4 \%$ for patients with incidentally discovered CMs. ${ }^{20}$ However, the 5-year risk of developing epilepsy among patients presenting with a first-time seizure without hemorrhage or focal deficit was $94 \%$. Another study of 107 patients with incidental cerebral CMs reported no new seizures over a median follow-up of 12.5 years (total of 1311 patient-years). ${ }^{28}$

\section{Limitations of This Study}

This is a study of CM hemorrhage risk, a component of the entity's natural history. It is limited by the heterogeneity of incorporated reports and study designs. As mentioned, some studies recruited patients based on imaging review, while others included patients evaluated prior to anticipated treatment, introducing potential bias. All studies were limited by selection bias as patients may be selected out for early treatment. Although our overall hemorrhage rates were calculated across multiple studies, we were unable to accumulate adequate data from our reviewed studies to provide pooled hemorrhage rates for CM subclasses, such as unruptured versus ruptured CMs. Only 5 studies were incorporated in our pooled evaluation of hemorrhage risk factors. Selective outcome reporting of statistically significant results may have limited our analysis; however, all hemorrhage rates and hazard ratios provided in each study were incorporated in our analysis. We were unable to formally evaluate all potential risk factors such as pregnancy, prior radiation, and antithrombotic treatment.

\section{Conclusions}

We report an overall annual hemorrhage rate of $2.5 \%$ per patient-year for cerebral CMs (95\% CI $1.3 \%-5.1 \%$ ). Prior hemorrhage was a risk factor for subsequent hemorrhage, while patient sex, lesion size, location, multiplicity, and radiographically apparent associated DVAs were not.

\section{References}

1. Abla AA, Lekovic GP, Turner JD, de Oliveira JG, Porter R, Spetzler RF: Advances in the treatment and outcome of brainstem cavernous malformation surgery: a single-center case series of 300 surgically treated patients. Neurosurgery 68:403-415, 2011
2. Aiba T, Tanaka R, Koike T, Kameyama S, Takeda N, Komata T: Natural history of intracranial cavernous malformations. J Neurosurg 83:56-59, 1995

3. Al-Shahi Salman R, Hall JM, Horne MA, Moultrie F, Josephson CB, Bhattacharya JJ, et al: Untreated clinical course of cerebral cavernous malformations: a prospective, populationbased cohort study. Lancet Neurol 11:217-224, 2012

4. Barker FG II, Amin-Hanjani S, Butler WE, Lyons S, Ojemann RG, Chapman PH, et al: Temporal clustering of hemorrhages from untreated cavernous malformations of the central nervous system. Neurosurgery 49:15-25, 2001

5. Cakirer S: De novo formation of a cavernous malformation of the brain in the presence of a developmental venous anomaly. Clin Radiol 58:251-256, 2003

6. Campeau NG, Lane JI: De novo development of a lesion with the appearance of a cavernous malformation adjacent to an existing developmental venous anomaly. AJNR Am J Neuroradiol 26:156-159, 2005

7. Cantu C, Murillo-Bonilla L, Arauz A, Higuera J, Padilla J, Barinagarrementeria F: Predictive factors for intracerebral hemorrhage in patients with cavernous angiomas. Neurol Res 27:314-318, 2005

8. Clatterbuck RE, Moriarity JL, Elmaci I, Lee RR, Breiter SN, Rigamonti D: Dynamic nature of cavernous malformations: a prospective magnetic resonance imaging study with volumetric analysis. J Neurosurg 93:981-986, 2000

9. Cutsforth-Gregory JK, Lanzino G, Link MJ, Brown RD Jr, Flemming KD: Characterization of radiation-induced cavernous malformations and comparison with a nonradiation cavernous malformation cohort. J Neurosurg 122:1214-1222, 2015

10. Dammann P, Wrede KH, Maderwald S, El Hindy N, Mueller $\mathrm{O}$, Chen B, et al: The venous angioarchitecture of sporadic cerebral cavernous malformations: a susceptibility weighted imaging study at 7 T MRI. J Neurol Neurosurg Psychiatry 84:194-200, 2013

11. Del Curling O Jr, Kelly DL Jr, Elster AD, Craven TE: An analysis of the natural history of cavernous angiomas. J Neurosurg 75:702-708, 1991

12. Detwiler PW, Porter RW, Zabramski JM, Spetzler RF: De novo formation of a central nervous system cavernous malformation: implications for predicting risk of hemorrhage. Case report and review of the literature. J Neurosurg 87:629-632, 1997

13. Erdur H, Scheitz JF, Tütüncü S, Fiebach JB, Endres M, Werring DJ, et al: Safety of thrombolysis in patients with acute ischemic stroke and cerebral cavernous malformations. Stroke 45:1846-1848, 2014

14. Flemming KD, Link MJ, Christianson TJ, Brown RD Jr: Prospective hemorrhage risk of intracerebral cavernous malformations. Neurology 78:632-636, 2012

15. Flemming KD, Link MJ, Christianson TJ, Brown RD Jr: Use of antithrombotic agents in patients with intracerebral cavernous malformations. J Neurosurg 118:43-46, 2013

16. Gross BA, Du R: Cerebral cavernous malformations: natural history and clinical management. Expert Rev Neurother 15:771-777, 2015

17. Gross BA, Du R, Orbach DB, Scott RM, Smith ER: The natural history of cerebral cavernous malformations in children. J Neurosurg Pediatr 17:123-128, 2016

18. Gross BA, Lin N, Du R, Day AL: The natural history of intracranial cavernous malformations. Neurosurg Focus 30(6):E24, 2011

19. Jeon JS, Kim JE, Chung YS, Oh S, Ahn JH, Cho WS, et al: A risk factor analysis of prospective symptomatic haemorrhage in adult patients with cerebral cavernous malformation. J Neurol Neurosurg Psychiatry 85:1366-1370, 2014

20. Josephson CB, Leach JP, Duncan R, Roberts RC, Counsell $\mathrm{CE}, \mathrm{Al}$-Shahi Salman R: Seizure risk from cavernous or 
arteriovenous malformations: prospective population-based study. Neurology 76:1548-1554, 2011

21. Kalani MY, Zabramski JM: Risk for symptomatic hemorrhage of cerebral cavernous malformations during pregnancy. J Neurosurg 118:50-55, 2013

22. Kim DS, Park YG, Choi JU, Chung SS, Lee KC: An analysis of the natural history of cavernous malformations. Surg Neurol 48:9-18, 1997

23. Kondziolka D, Lunsford LD, Kestle JR: The natural history of cerebral cavernous malformations. J Neurosurg 83:820824,1995

24. Li D, Hao SY, Jia GJ, Wu Z, Zhang LW, Zhang JT: Hemorrhage risks and functional outcomes of untreated brainstem cavernous malformations. J Neurosurg 121:32-41, 2014

25. McCormick WF: The pathology of vascular ("arteriovenous") malformations. J Neurosurg 24:807-816, 1966

26. McCormick WF, Nofzinger JD: "Cryptic" vascular malformations of the central nervous system. J Neurosurg 24:865875,1966

27. Moher D, Liberati A, Tetzlaff J, Altman DG: Preferred reporting items for systematic reviews and meta-analyses: the PRISMA statement. J Clin Epidemiol 62:1006-1012, 2009

28. Moore SA, Brown RD Jr, Christianson TJ, Flemming KD: Long-term natural history of incidentally discovered cavernous malformations in a single-center cohort. J Neurosurg 120:1188-1192, 2014

29. Moriarity JL, Wetzel M, Clatterbuck RE, Javedan S, Sheppard JM, Hoenig-Rigamonti K, et al: The natural history of cavernous malformations: a prospective study of 68 patients. Neurosurgery 44:1166-1173, 1999

30. Otten P, Pizzolato GP, Rilliet B, Berney J: [131 cases of cavernous angioma (cavernomas) of the CNS, discovered by retrospective analysis of 24,535 autopsies.] Neurochirurgie 35:82-83, 128-131, 1989 (Fr)

31. Porter PJ, Willinsky RA, Harper W, Wallace MC: Cerebral cavernous malformations: natural history and prognosis after clinical deterioration with or without hemorrhage. J Neurosurg 87:190-197, 1997

32. Rigamonti D, Drayer BP, Johnson PC, Hadley MN, Zabramski J, Spetzler RF: The MRI appearance of cavernous malformations (angiomas). J Neurosurg 67:518-524, 1987

33. Rigamonti D, Hadley MN, Drayer BP, Johnson PC, HoenigRigamonti K, Knight JT, et al: Cerebral cavernous malfor- mations. Incidence and familial occurrence. N Engl J Med 319:343-347, 1988

34. Robinson JR, Awad IA, Little JR: Natural history of the cavernous angioma. J Neurosurg 75:709-714, 1991

35. Sarwar M, McCormick WF: Intracerebral venous angioma. Case report and review. Arch Neurol 35:323-325, 1978

36. Schneble HM, Soumare A, Hervé D, Bresson D, Guichard JP, Riant F, et al: Antithrombotic therapy and bleeding risk in a prospective cohort study of patients with cerebral cavernous malformations. Stroke 43:3196-3199, 2012

37. Vernooij MW, Ikram MA, Tanghe HL, Vincent AJ, Hofman A, Krestin GP, et al: Incidental findings on brain MRI in the general population. N Engl J Med 357:1821-1828, 2007

38. Witiw CD, Abou-Hamden A, Kulkarni AV, Silvaggio JA, Schneider C, Wallace MC: Cerebral cavernous malformations and pregnancy: hemorrhage risk and influence on obstetrical management. Neurosurgery 71:626-631, 2012

39. Zabramski JM, Wascher TM, Spetzler RF, Johnson B, Golfinos J, Drayer BP, et al: The natural history of familial cavernous malformations: results of an ongoing study. J Neurosurg 80:422-432, 1994

\section{Disclosures}

The authors report no conflict of interest concerning the materials or methods used in this study or the findings specified in this paper.

\section{Author Contributions}

Conception and design: Gross. Acquisition of data: both authors. Analysis and interpretation of data: both authors. Drafting the article: Gross. Critically revising the article: both authors. Reviewed submitted version of manuscript: both authors. Approved the final version of the manuscript on behalf of both authors: Du. Statistical analysis: Du. Administrative/technical/ material support: Du. Study supervision: Du.

\section{Correspondence}

Rose Du, Department of Neurological Surgery, Brigham and Women's Hospital and Harvard Medical School, 75 Francis St., Boston, MA 02115. email: rdu@partners.org. 